\title{
TRABALHO INFANTIL: UM VELHO PROBLEMA NA ORDEM DO DIA
}

Honor de Almeida Neto*

SÍNTESE - A discussão em tomo da questão do trabalho infantil está hoje na ordem do dia dos principais paises do mundo. O mercado mundial cada vez mais globalizado e competitivo pressiona sobretudo os paises em desenvolvimento a erradicar esse tipo de trabalho. A inserção precoce da criança no mercado acaba comprometendo seu acesso a instâncias formativas que podem potencializar a sua conquista à cidadania. Este artigo pretende articular as categorias globalização, formação e cidadania com a questão do trabalho infantil, chamando atenção para os prejuizos ou possibilidades de mudança dessa realidade, bem como para os interesses que estão por trás das diversas ações e campanhas voltadas à sua erradicação.

PAIAAVRAS-CHAVE - trabalho infantil, formação e cidadania.
ABSTRACT - The discussion about the issue of child labor is currently in the agenda of the main countries of the world. The world market increasingly globalized and competitive exerts pressure especially on developing countries so that they will eradicate this type of labor. The precocious insertion of a child in the market ends up harming his/her access to formative resources that can make his/her conquer of citizenship possible. This article intends to articulate the categories globaization, formation, and citizenship with the issue of child labor by focusing on the damages or possibilities of change for this reality, as well as focusing on the interests that are behind the different actions and campaigns devoted to its eradication.

KEY WORDS - child labor, formation and citizenship.

A preocupação em torno da questão do trabalho infantil em nível mundial não é um fenômeno recente. $O$ Velho Testamento traz passagens que demonstram a preocupação com tal problema, já no século VI a.C. Na virada do século XVIII, o trabalho infantil nas fábricas inglesas chegou a um nível tão preocupante que provocou a criação da orr (Organização Internacional do Trabalho) em 1919. Mais recentemente, em 1990, essa organização recebeu um grande apoio do governo alemão que lançou uma ofensiva global contra o trabalho infantil culminando com a criação do IPEC (International Program on the Elimination of Child Labour) e conta com o apoio político e financeiro de diversos países. Tal fato é um forte indício de que o embate em torno da questão do trabalho infantil tem-se intensificado nos últimos anos.

* Bacharel e licenciado em Ciências Sociais, mestrando em Serviço Social, bolsista do CNPq (Conselho Nacional de Desenvolvimento Científico e Tecnológico).

\begin{tabular}{|l|l|l|l|l|l|}
\hline VERITAS & Porto Alegre & v. 43 & $\mathrm{n}^{\mathbf{0}}$ especial & Dezembro 1998 & p. 21-26 \\
\hline
\end{tabular}


No Brasil, a mobilização social pela erradicação do trabalho infantil aumentou a partir da década de 80, resultando na criação do ECA (Estatuto da Criança e do Adolescente) que representa um avanço do ponto de vista legal devido às mudanças conceituais e, em decorrência, nas práticas de atendimento à criança e ao adolescente. A nova lei expressa a concepção de que esses sujeitos, por se encontrarem em fase especial de desenvolvimento, são merecedores de proteção integral aos seus direitos, e a garantia a seu futuro deve ser tratada como prioridade absoluta da família, do Estado e da sociedade.

No entanto, continua a exploração da mão-de-obra infantil que cresce em todos os países do mundo. A Organização Internacional do Trabalho (ОIт) calcula que atualmente são 200 milhões de crianças trabalhando no planeta. Segundo o IBGE (Instituto Brasileiro de Geografia e Estatística), 7,5 milhões de brasileiros entre 10 e 17 anos trabalham, o que representa $11,6 \%$ da força de trabalho do país, e 3,5 milhões deles têm menos de 14 anos. Trata-se de mão-de-obra mais dócil e mais barata: em $70 \%$ dos casos, recebem em média meio salário-mínimo.

Embora o trabalho infantil não seja um fenômeno novo ${ }^{1}$ no Brasil, o agravamento dessa questão está relacionado com as mudanças ocorridas no sistema de produção. O processo de globalização, sob a hegemonia dos interesses do mercado, tem diminuído sensivelmente os postos de trabalho em nível mundial.

\section{Trabalho infantil num mundo globalizado}

A crescente diminuição de postos de trabalho, ao mesmo tempo que favorece a entrada de mão-de-obra infantil no mercado, como meio de aumentar a renda familiar, já que esse fenômeno desemprega e reduz salários, faz com que, sobretudo no mercado informal (que por sua flexibilidade absorve a mão-de-obra infantil em grande escala), os espaços sejam cobiçados e ocupados pela mão-de-obra adulta, que passa assim a substituir a força de trabalho infantil ou a competir com ela. A escassez de postos de trabalho nos setores formais da economia impõe o aproveitamento dos espaços antes ocupados por crianças. O trabalhador adulto é levado a se submeter a uma condição de trabalho e de remuneração que antes "satisfaziam" apenas as crianças. Observa-se que dialeticamente, a globalização modifica a dinâmica do mercado de trabalho, na medida em que faz com que este absorva e expulse concomitantemente a mão-de-obra infantil.

Em contrapartida, medidas, tanto do Estado como da iniciativa privada, tomam força com a globalização, visando erradicar o trabalho infantil e deslocar a criança do trabalho para a escola, como forma de abrir espaços no mercado para a mão-de-obra adulta.

Outro fator, e talvez o mais preponderante, explica as crescentes iniciativas dos órgãos internacionais e do próprio governo brasileiro ligadas à questão do trabalho infantil: a preocupação dos países mais ricos do mundo com o baixo preço dos produtos exportados dos paises pobres, que se tornam competitivos pelo baixo custo de sua mão-de-obra, como a mão-de-obra infantil, por exemplo.

1 No Brasil, em 1825, foi elaborada por José Bonifácio de Andrada e Silva, uma lei vedando o trabalho insalubre e fatigante para escravos menores de doze anos (Corazza, apud Velloso, 1985). 
Por outro lado, ao empregador acaba sendo vantajoso utilizar-se de uma mãode-obra legal e eticamente mais aceita pelo mesmo custo, não precisando submeter seu produto ou sua empresa a retaliações advindas de pressões ${ }^{2}$ externas contra o uso da força de trabalho infantil. Outro argumento que justifica as iniciativas atuais de erradicação do trabalho infantil diz respeito ao fato de que a competição acirrada exige o melhor aproveitamento possivel das novas tecnologias produzidas, o que requer mão-de-obra mais qualificada. Isso supõe uma outra formação capaz de adaptar o trabalhador com o novo perfil exigido pelo mercado.

\section{Trabalho infantil e formação cidadã}

O conceito de cidadania está historicamente relacionado à aquisição de direitos por parte do cidadão, geralmente em relação ao Estado. Porém, em meio ao processo de globalização, o conceito pode extrapolar essa concepção surgindo como alternativa ao poder político do Estado e ao poder econômico do mercado e passar a ser entendido em sua dimensão global, articulado através da organização de uma sociedade civil mundial. Essa articulação é impulsionada por demandas universais dos indivíduos, como, por exemplo, a questão do desemprego, da degradação ambiental, do direito à liberdade de expressão, à paz e até mesmo relativa a questões éticas, como a evolução da biogenética.

É possivel afirmar que o surgimento de uma sociedade civil global, participativa e consciente dos seus problemas locais e da identificação destes problemas com questões universais, passa pela formação dos agentes que a compõem. Nessa perspectiva, a formação do individuo, voltada para o seu ingresso no mercado, embora não garanta a criação ou a manutenção de postos de trabalho em quantidade suficiente para a absorção de toda a mão-de-obra disponivel, permite ao trabalhador ou futuro trabalhador a aquisição de diversos saberes que podem ser entendidos como condição fundamental para a conquista da cidadania por parte desse agente e para a formação de uma sociedade civil global, capaz de organizarse a ponto de impor suas demandas como prioritárias em contraposição às demandas do mercado.

É de suma importância que se perceba o trabalho infantil, sobretudo no Brasil, como um entrave para a constituição de uma cidadania planetária, visto que esta pressupõe organização, participação política e tomada de consciência de problemas comuns, o que nos parece difícil de imaginar diante do contexto em que são formados os trabalhadores infantis.

O mundo do trabalho de hoje exige de sua mão-de-obra não apenas a qualificação - entendida esta como uma habilidade específica requerida para a execução de determinada tarefa - mas pede presença de espírito, equilibrio emocional e sobretudo capacidade para não resistir ao novo, à mudança. Logo, exige saberes

2 Como exemplo de pressões externas podemos citar, além do boicote dos países importadores, as iniciativas em nivel nacional de alguns empresários reunidos na Fundação Abrinq pelos Direitos da Criança. A Abrinq lança campanhas chamando atenção para o fato de que, nos produtos identificados através do seu selo de qualidade, não é utilizada mão-de-obra infantil, deixando a cargo do consumidor o julgamento se é ou não correto, moral ou ético este tipo de prática (Nunes, 1997, p.7). 
que não mais dizem respeito somente a saberes técnicos, mas principalmente à qualificação social, que tende a se somar à importância da qualificação técnica. Assim, a formação exigida pelo mercado em certa medida sintoniza-se com uma capacitação cidadã.

Porém a formação através do trabalho infantil, no caso do Brasil, compromete a condição do agente enquanto homem, deslocando a sua faixa etária e fazendo com que ele se desenvolva num estado desigual, em constante estresse, por exemplo. Esse deslocamento se refere à inserção da criança num universo de trabalho que exige dela uma série de interações que não são condizentes com sua idade cronológica, tanto mental quanto fisicamente, pelo menos na comparação com outras crianças que, nesta faixa etária, têm a possibilidade de experimentar outros tipos de interações, ocupando seu tempo com atividades mais favoráveis a uma formação voltada para a cidadania, e não com a busca de recursos para sua sobrevivência como ocorre com os trabalhadores infantis brasileiros.

Observa-se que os efeitos negativos do processo de globalização tornam também globais as necessidades de atuação e organização para combatê-los. Neste sentido ele é contraditório, sobretudo quando exige uma nova qualificação dos seus agentes. O processo é semelhante, por exemplo, a forma como ocorria no capitalismo industrial, onde a extração de mais-valia do proletariado era concomitante com a potencial possibilidade de organização dos trabalhadores em sindicatos ou conselhos de fábricas, capazes de reverter ou amenizar sua condição de exploração e de ampliar os seus direitos.

Levando-se em conta que grande parte da formação do indivíduo, sobretudo com vistas ao futuro ingresso no mercado de trabalho, acontece num contexto de escola, parece relevante que chamemos a atenção para o fato de que o modelo atual de ensino não se constitui numa alternativa ao trabalho infantil. Sua reformulação é urgente como forma de despertar o interesse pela escola, tornando-a mais atrativa e producente para a criança do que o trabalho. Além disso, há a necessidade de adaptá-la à realidade do aluno, de tal modo que se torne mais útil e mais prática para esse tipo de população.

Embora não seja objetivo deste artigo esmiuçar a realidade do trabalhador infantil brasileiro, cabe ressaltar que a prática que ele realiza apresenta-se incompatível com sua formação escolar trazendo sérios prejuízos à criança estudante. Estes prejuizos se referem ao ritmo de trabalho que, por vezes, impede a freqüência à escola e consome toda a energia necessária a uma atenção satisfatória na sala de aula, além dos prejuízos físicos, como o fato de essas atividades por vezes consumirem reservas de resistências que deveriam durar até a idade adulta. Somado a isso, o ambiente social do trabalho diminui o valor que a criança dá à educação, fato comum particularmente entre as crianças de rua. A carência econômica impossibilita o acesso às diversas instâncias de formação extra-escolares, como os diversos cursos existentes, a informação advinda da televisão, da rede mundial de computadores, de leituras, entre outras. 


\section{Considerações finais}

Conforme o Estatuto da Criança e do Addolescente (ECA): “[...] é dever de todos prevenir a ocorrência de ameaça de violação dos direitos da criança e do adolescente" (ECA, art. 37). Nesse sentido, através de uma pesquisa que realizo junto aos entregadores de jornais e vendedores de alho da cidade de Porto Alegre, investigo os saberes adquiridos por esses agentes através das relações que estabelecem com o meio, a fim de perceber a forma pela qual estão sendo formados. Partindo do pressuposto de que o trabalho infantil se dá no âmbito das relações de poder, onde há um alto grau de submissão e de dominação, pretendo reconstituir os campos sociais em que esses agentes se encontram, para melhor captar as disputas que se estabelecem nas relações que os constituem enquanto cidadãos.

Pressupõe-se que o não-acesso dos trabalhadores infantis às novas instâncias formativas, potencialmente ricas para o desenvolvimento da cidadania e para a diminuição do apartheid econômico e social a que são submetidas, aparece como mais um indicativo dos efeitos nefastos de sua prática, justificando toda e qualquer intervenção, seja estatal ou não estatal, que vise a sua erradicação.

Diante disso, estratégias tanto do Estado como da sociedade civil que, na busca pela erradicação do trabalho infantil, visam deslocar a criança trabalhadora do mercado de trabalho para a escola, tendem a agravar a condição social desses agentes, se forem isoladas de alternativas de geração de emprego e sobretudo de renda familiar. Isto se deve ao fato de que o trabalho se constitui numa aiternativa de sobrevivência da criança em meio à realidade excludente que lhe é imposta pela dinâmica do sistema capitalista. Dinâmica esta que não é substancialmente modificada com sua inclusão no nosso defasado sistema escolar, além de continuar a expulsar a mão-de-obra adulta do mercado, empurrando a criança novamente para o trabalho.

É dificil imaginar que crianças precocemente envolvidas na luta pela sobrevivência, pela renda, sujeitas a toda espécie de intempéries comuns a uma atividade que, sendo ilegal por sua natureza, não pode ser regularizada ou fiscalizada, tenham acesso a instâncias formativas que lhe permitam a aquisição de saberes potencialmente capazes de facilitar o seu ingresso no mercado atual e/ou uma emancipação politica ou cultural que lhe permita lutar pelos seus direitos de cidadão.

\section{Referências bibliográficas}

BASTIANI, Roshangela Freitas. O trabalhador-criança no Rio Grande do Sul. Porto Alegre, PUCRS, 1986, Mestrado.

DESAULNIERS, Julieta B. R. Formação ou qualificação, ou competência...In: Veritas, Porto Alegre: Edipucrs, v. 38, n. 149, mar. 1993.

jun. 1997. 1997.

DIMENSTEIN, Gilberto. Como a criança mudou a agenda da imprensa brasileira. São Paulo, 1997.

NUNES, Edson. Cadeia de produçäo econômica. Internet/ http://cogeae.pucsp.br/-sircri/banco/vida/ trabalho/cadeia.html,Pucsp, 1997. 
CORAZZA, Vera. O trabalho do menor no Brasil - um estudo comparativo nas regiões metropolitanas (Porto Alegre - São Paulo - Recife). Porto Alegre, PuCRs, 1986 (tese de mestrado).

DEMO, Pedro. Cidadania tutelada e cidadania assistida. Campinas: Autores Associados, 1995.

JOHNSON, Allan G. Dicionánio de Sociologia: guia prático da linguagem sociológica. Rio de Janeiro: Jorge Zahar, 1997.

PIRES, J. M. Trabalho infantil, necessidade e a persistência. In: Justificativa de Ordem Social, Internet: http://cogeae.pucsp.br/-sircri/banco/vida/trabalho/jsoc.html, PUCSP, 1997.

QUEM explora a mão-de-obra infantil, Revista Atenção, São Paulo, Página Aberta, p. 8-16, dez./jan. 1996.

SLVA, Inês Amaro da. Competência e cidadania no mundo do trabalho... Veritas, Porto Alegre, Edipucrs, v. 42, n. 2 jun. 1997.

TRABALHO infantil: infância roubada. Folha de São Paulo, São Paulo, $1^{\circledR}$ maio 1997.

VIEIRA, Liszt. Cidadania e globalização. Rio de Janeiro: Record, 1997. 